\title{
Collective Decision-Making in Complex Situations: a Dynamic Role in Alert Management
}

\author{
Charlotte Gaudin 1, 2,5 \\ ${ }^{1}$ Research center in Psychology of Cognition, Language and \\ Emotion (PSYCLE, E.A 3273) \\ Aix-Marseille University \\ ${ }^{2}$ Laboratoire d'Enseignement et de Recherche sur le \\ Traitement de l'Information Médicale (LERTIM, EA 3283) \\ Faculty of Medecine, Aix Marseille University \\ charlotte.gaudin@etu.univ-provence.fr
}

\author{
Nathalie Bonnardel ${ }^{1,3}$ \\ ${ }^{1}$ Research center in Psychology of Cognition, \\ Language and Emotion (PSYCLE, E.A 3273) \\ Aix-Marseille University \\ ${ }^{3}$ University Institute of France \\ Nathalie.Bonnardel@univ-provence.fr
}

\author{
Liliane Pellegrin ${ }^{4}$ \& Hervé Chaudet ${ }^{2,5}$ \\ ${ }^{4}$ Department of Telemedicine, \\ Institut de Médecine Navale du Service de Santé des Armées (IMNSSA), TOULON \\ ${ }^{5}$ Unité de Recherche Epidémiologique - Département d'Epidémiologie et de Santé Publique \\ Institut de Médecine Tropicale du Service de Santé des Armées (IMTSSA) \\ 1.pellegrin@imnssa.net, $\underline{\text { lhcp@acm.org }}$
}

\begin{abstract}
Motivation - This paper presents collective processes analysis in command and control activities. Research approach - Our objective is to describe the collective activities during alert management situations using the EORCA method (Event Oriented Representation of Collaborative Activities). Findings/Design -Data analysis allows us to characterize different inter-individual processes: co-operation and collaboration. Results show that they consist mainly in primarily communication procedures between experts during the varying phases of about management. Research limitations/Implications - Only one setting (epidemiological alert management) was investigated in this study, which limited a possible generalisation of the findings. Originality/Value - The research makes a contribution to the need of designers to target specific collective processes used in alert management by creating specific design for crisis centre. Take away message - Different team activity processes occur during the course of action in alert management, which correspond to specific phases: cooperation during information elements acquisition; collaboration during situation assessment and decision making phases.
\end{abstract}

\section{KEY WORDS}

Inter-individual collaboration and co-operation; team activity analysis; decision-making; alert management; complex and time-constrained situation

\section{INTRODUCTION}

This work tackles the way collective processes are used during alert management activities. Decision-making research is currently influenced by two main approaches: the study of individual decision making processes and the study of team decisions, in controlled environments or in natural settings (Patel and Arocha, 2001). In naturalistic setting, decisions are embedded in a broader situational and cultural context, and are part of a dynamic decision process (Orasanu and Connoly, 1993). In this work we have investigated a naturalistic setting dealing with decision-making processes in collaborative mode during alert management situations within the Health Service of the French Forces (SSA). It relates to a syndromic alert project in near real time (ASTER Alert Syndromique en TEmps Réel). From a public health perspective, the French Forces are particularly exposed to biological and medical risks, in various natural environments. It is the reason why the Institute of Tropical Medicine of the Health service of the Armies has developed a real time epidemiological surveillance system. This system aims at detecting any worldwide epidemiologic event that may have an impact on the forces and it contributes to the medical risk management process within French forces. This project is the substructure of an epidemiologic expertise centre (CESIE) comprising a team of experts and ASTER system. On the basis of the recognition of visual signals on screens, the team assesses the situation and elaborates countermeasures decisions. They need to identify the situation as soon as possible in order to manage it as effectively as possible. 
The main objective of this study is to analyze team activities during decision-making processes in a complex and dynamic context. Towards this end, we choose to use EORCA method (Event Oriented Representation of Collaborative Activities, EORCA, Pellegrin, Bonnardel, Antonini, Albanese, Martin, Chaudet, 2007): a formal method describing collective activities in complex situations. This communication is organised as follows. First, we present the rationale in collaborative decision-making that has guided our research. Then we describe the method we used as well as results concerning the alert management activity. Finally we conclude with the presentation of a first model of alert management and the collective characteristics of this activity.

\section{BACKGROUND AND DEFINITIONS}

\section{Alert Management: a Command and Control System}

Command and control (C2) systems involve several operators working on a technical system who use multiple information sources and a "distributed knowledge" (information on time and location of events, knowledge of the specific situation, exploratory knowledge, experience). To make C2 function as a whole, all "parts" need to be well coordinated in accordance with the concept of team and collaborative work. Such command and control systems are based on the management of various socio-technical factors, such as staff, procedures, equipments and other resources in order to fulfill functions of planning, direction, coordination and control of operations to meet organizational goals (Wallenius, 2002).

Epidemiologic alert management using ASTER may be considered as a specific C2 system related to Forces' health, characterized by a decision-making activity in a complex situation, and emphasizing the role of both "Distributed Cognition" and "Naturalistic Decision Making" (NDM) as theoretical approaches. Hutchins (1995) presents Distributed Cognition as a view on how information is transformed and propagated around a system. Naturalistic Decision Making research concerns the decision strategies people use in bringing their expertise to bear under challenging real world conditions as fire units, military command and control setting (Klein, 1993). Finally, in order to define and describe precisely this activity, we use existing models of decision-making in complex situations (Rasmussen, 1994; Klein, 1993; Endsley, 1995).

\section{Team Activities}

Since the importance of teams increases in complex environments, operators' activities should be analysed not only at an individual level but also at the level of the team. Salas (2004) defines a team as a group of, at least, two persons, dealing with multiple resources of information, who work in order to achieve a common objective. In addition, according to Cooke (2004) teams must perform several activities as an integrated unit and coordinate several cognitive processes: detection and interpretation of information elements, remembering, reasoning, planning, solving problems, acquiring knowledge and making decisions. Then the passage from the individual to the group leads to reinforce the importance of the time and location parameters in the activity analysis. In reference with cognitive and social psychology, numerous definitions concern team activity. Several approaches (Leplat, 1994; Karsenty and Pavard, 1997) consider team activity as a task expecting the coordinated intervention of several operators in order to achieve common goals. Different concept of team activity, such as co-operation, coordination, collaboration and communication, are important to be defined.

Co-operation happens when operators pursue goals that can interfere in their results or in their procedures. Operators have to deal with these interferences and have also to enable their activity each other (Maggi, 1996; Hoc, 1996). According to Maggi (1996), co-operation does not require a time and location unity and direct communications. The coordination can be seen as the whole rules that manage and control co-operation activity (Maggi, 1996). Christfferson and Woods (2002) previously considered 'coordination across agents in the system as at least important as the performance of the individual agent taken in isolation'.

Collaboration corresponds to the dynamic allocation of functions between the team operators. They pursue the same goals and they work together in order to achieve them. At last, communications are activity indicators, and allow individual actions performance (Savoyant and Leplat, 1983). Communication analyses allow the examination and modelling of team activity (Benchekroun and Weill-Fassina, 2000). Collaboration and cooperation between actors require a mental synchronization, which correspond to the construction of a shared representation as well as temporal synchronization of actions. The information acquisition and the development of a common ground or reference frame are essential in collaborative activities. A reference frame, is jointly elaborated by individuals who are involved in the preparation and the performance of actions. It is the result of a confrontation between individuals who take part into a group (De Terssac and Chabaud, 1990).

Inter-individual and man-machine collaborations in the alert management context depend on collective processes of several agents that are distributed at various levels (e.g., ground, centre of analysis, decision-making centre). 


\section{Decision-Making in Dynamic Situation}

From an ergonomic psychology point of view, diagnosis and decision-making activities are essential during alert management activities. Operators involved in alert management must detect as early as possible any health event and evaluate the situation.

These teams of experts need to perceive, interpret and exchange a great quantity of frequently ambiguous information elements with the aim of developing a high level of Situation Awareness (SA) required in decisionmaking activities. Situations Awareness refers to the perception of situation's elements, in a time and a given space, the comprehension of their direction and the projection of their statute in an immediate future (Endsley, 1995). The processed data are generally ambiguous, the environments dynamics dubious and complex, which leads us to introduce again the concept of NDM (Naturalistic Decision Making, Klein, 1993). This approach seeks to understand and explain how experts work individually or collectively in situations characterized by strong temporal constraints, how they evaluate the situation, make decisions and perform actions. The health events have their own dynamic; these crisis situations develop independently of the actions of the various actors controlling the process. They comprise phases of diagnosis and decision-making. Previous research in cognitive and ergonomic psychology conduct on medical diagnosis highlighted two fundamental characteristics. First, we consider the diagnosis of the situation (integrating the forecast) as an activity of comprehension of a relevant situation to a decision of action" (Hoc and Amalberti, 1994). In addition, these decision-makings are done in a complex situation at risk (for the population concerned) and having strong temporal constraints. The epidemiological diagnosis of situation can be considered as tasks of problem solving. It can correspond to a routine in usual epidemiologic situations and require the activation of knowledge in rare and complex cases. The results of diagnosis lead to decision-making with the aim of determining and managing an alert, as well as building countermeasures (Rasmussen, 1994).

In his "Recognition Primed Decision Model" (RPD model, Klein, 1993), two types of situations in which the experts use their experience and their knowledge to deal with a situation that can be either a routine's situation or a complex situation. Experts use typical responses and outcomes in situations they likely identify as similar to past ones. They recognize situations or scenarios and they compare them with clusters of knowledge concerning certain situations. These stored memory representations are called schemata (Federico, 1995). If the situation does not seem familiar, the decision maker adjusts the option after evaluating it (Klein, 1993).

\section{OBJECTIVES}

The objective of this study is to characterize the nature of team activities during alert management situations. Precisely, we describe collective processes during each phases of the alert management. In order to obtain indicators, we observed an exercise of simulation of an epidemiologic alert within the French forces. These observations allow us to determine whether complex situations are solved in collective modes. In addition, this study aims at modelling alert triggered events, including data analysis and procedural aspects (kinds of action, information elements, expert network).

\section{MATERIALS AND METHODS}

\section{Preliminary Study}

A preliminary study consisted in an analysis of the alert management simulation, initially developed within the department of Epidemiology and Public health of the Force Health Service. Semi directed interviews were conducted with doctors and veterinary of the units of this department. These interviews made it possible to formalize their activity with use the MAD method: Analytical Method of Description of task (Bisseret, Sébillotte, Falzon, 1999). They allow the construction of intermediate trees MAD centred on the task of alert management, which made it possible to detail all the actions necessary to the good course of actions of this task, and to organize them according to a logical order representative of their activity. Three types of actions were raised: the acquisition of information associated with 'data validation loop', the situation assessment, and decision-making. These results stress the importance of actions correspond to the search and the communication of information elements. Moreover, this analysis made it possible to bring closer the alert management activity to the 'Skill-Rule-Knowledge' model (Rasmussen, 1994).

\section{Study of the Management of an Alert}

\section{Context of the Study}

The French Force Health Service was invited by NATO to take part in an international exercise of medical crisis simulation. This exercise simulated two outbreaks within an inter-allied deployment to Afghanistan (natural and intentional). It was held during a three days exercise representing 6 simulated days. Surveillance data were transmitted by the animator of the exercise (in Munich, DSS) to the participants (three actors in Marseille). The data concerning the French deployment were monitored by ASTER in Marseille, according to a rythm 
simulating a real unfolding. This simulation constituted the material of this study. It allowed systematized observations and the examination of collective activities performed by the experts during the alert management, including diagnosis and decision-makings phases.

\section{Participants}

The actors of this exercise in Marseille were IMTSSA's physicians, including an epidemiologist, a specialist in medical intelligence and a physician with a double speciality (epidemiologist and medical informatics). They collaborated with another epidemiologist from their team and an inter-allied epidemiologic surveillance team located in Münich.

\section{Material: observation}

Direct observations of the operators, a systematized collection of undertaken actions and direct or indirect communications (telephone and e-mail) between the various actors constitute the material. The whole set of the electronic communications between participants have been analysed. In addition, we introduced post-tasks interviews with the participants, focused on the alert management activity and their mental representations of this activity.

\section{Method of analysis of the data: EORCA}

The method we used, consists in analysing the collaborative actions during the alert management activity in real time. Towards this end, the EORCA method (Event Oriented Representation of Collaborative Activities; Pellegrin \& als. 2007) allows the description of the activity starting from observations. Its objective is to formally describe the actions of collaboration between operators in dynamic situation. The final representation of this activity is based on an event-driven formalism.

With regard to the formalization of the events, EORCA is based on a formal language of space-time representation of aggregate events (STEEL, Spatio-temporal Extended Event Language, Chaudet, 2004). This method is composed of three successive stages. The first relates to the structured collection of observations allowing the identification of sequences of events. The observations must be organized chronologically, located in space, and described in a homogeneous way for their analysis. An "observed event" associates an action with one or more actors (a doctor, a whole of doctors, a team...). An event is an occurrence of action carried out by (or occurring with) one or more agents according to a given time and a place. The second stage corresponds to the "coding" of the observations according to a given formalization. For each event, actors and actions are coded with regard to an ontology, built according to the studied field of expertise, from which the higher classes result from DOLCE (Gangemi, 2002). Three main classes of actions are taken into consideration for analysing the total set of observations: speech acts (oral or written acts), non-informative actions (system preparation or adjustment) and informative actions (information acquisition).

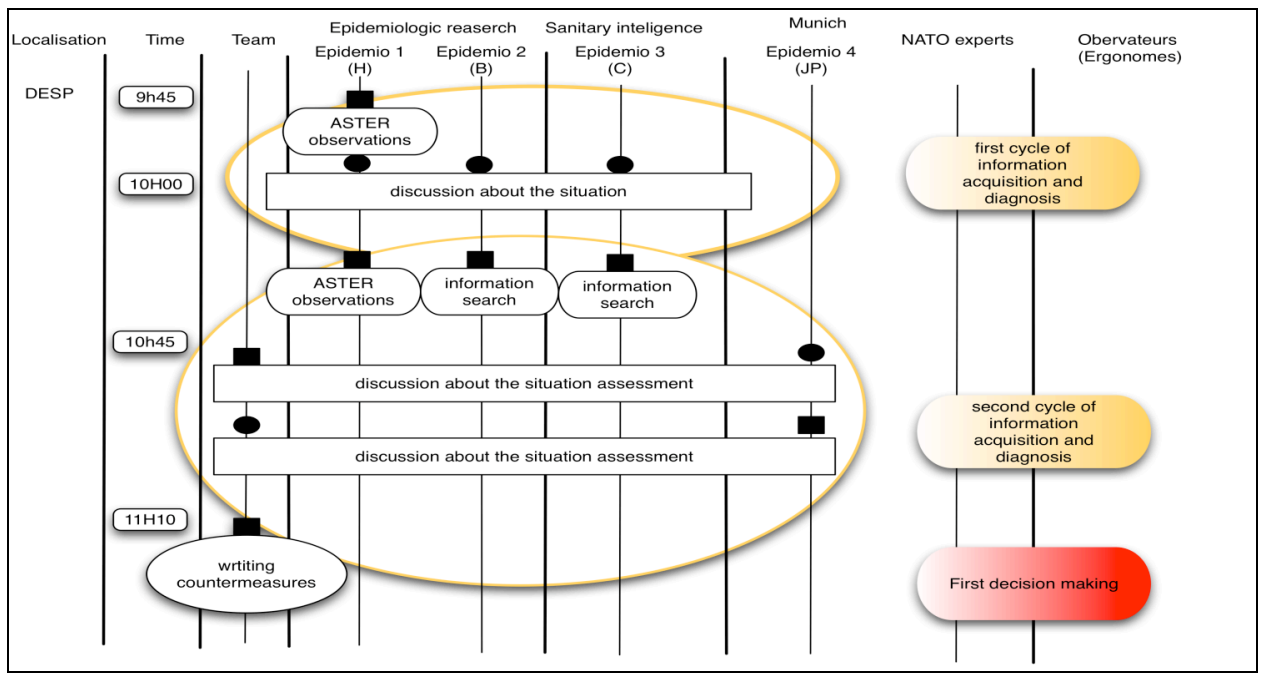

Figure 1. EORCA Graphical Representation (one cycle of decision making)

The third stage results in to the construction of the complete representation of events. We choose the following shapes to represent the classes of actions in the final sheet: regular rectangles for Speech acts between the actors, which refer to oral speeches or written acts that have been observed and transcribed in the observation sheet. Ovals for representing non-informative actions, which include all actions performed by team members, which bring no specific information during the situation (management of computerized systems and usage of 
tools). Round corner rectangle for informative actions, which include actions that require information acquisition and data management to deal with the current situation. Specialized tools, medical information systems or databases may support them (monitoring, general control of situation parameters, observations and verifications). A chart of the scenario is derived, which makes it possible to associate the whole of the actors, with regard to the actions composing the events structured temporally (see Figure 1). This graph will be useful for representing the various individual and collective tasks the agents will have to perform.

\section{RESULTS}

\section{Events EORCA Analyses}

We identified the various actors and actions. The events were listed in a table and presented in the graphical formalism. The indicators taken into consideration here are the type of action and their frequency of appearance. A descriptive analysis will be based on these indicators.

\section{Speech acts analysis}

With regard to the various types of actions, 149 actions are speech acts, 42 actions are informative ones and 20 are non-informative actions. This rate of speech acts highlights the crucial role of communications in the alert management activity (see Table 1).

\begin{tabular}{|l|l|}
\hline Main classes of actions & Effectives \\
\hline Non informative actions & $20(10 \%)$ \\
\hline Speech acts & $149(71 \%)$ \\
\hline Informative actions & $42(19 \%)$ \\
\hline Total & 211 \\
\hline
\end{tabular}

Table 1. Main Observed Classes of Actions

Focusing only on the corpus of speech acts, several types of information elements were the objects of communications. Within speech acts, communications concerning the elements of the situation assessment were more significant than those are related to the system use or to the conditions of the exercise. The results show that the large majority $(69 \%)$ of collective actions (speech acts) concern the situation assessment, during the situation diagnosis phases (Total of 103/149).

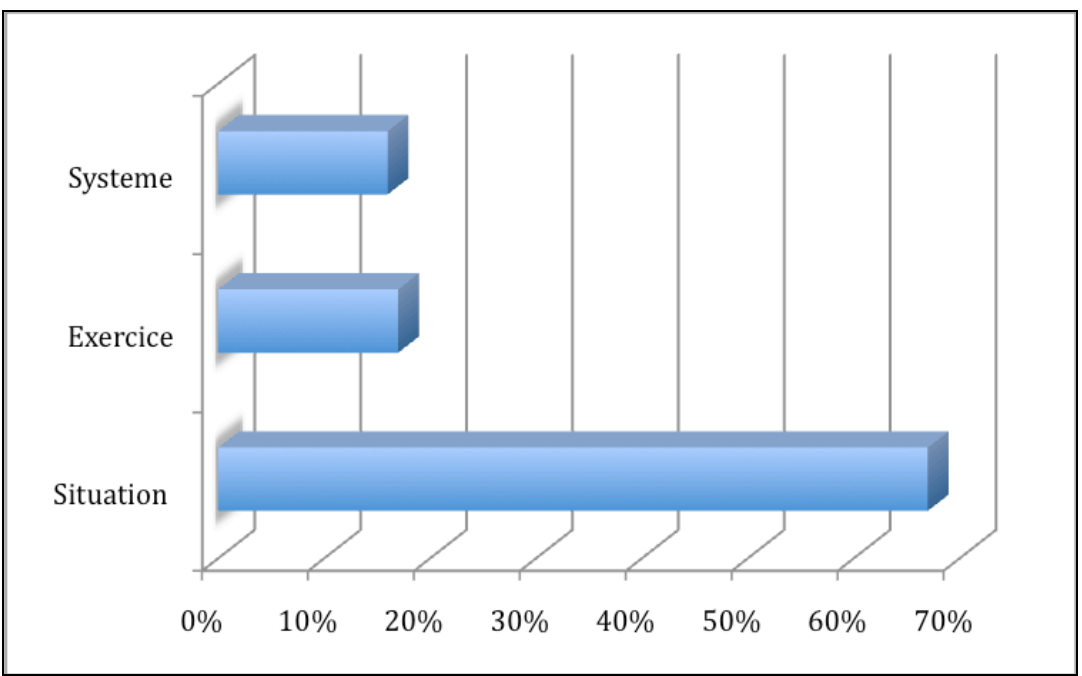

Figure 2. Effectives of Class Information Speech Acts

\section{Communication Modes}

E-mails communications were the most important in this setting because the actors were located in different places. Indeed, within the information transmission actions, 138 communications are "e-mail", 35 are "direct verbal communication" and 18 are "telephone call". These results stress the importance of the e-mail communication mode and so the use of machine for collaborations because of the asynchronous character of this situation. So, we have to consider the operator not like individual isolated but related to his/her system of work; it is a joint cognitive system.

\section{Team activity analysis}

The modelling with EORCA makes possible to highlight various stages for the operator or the team of experts identified throughout the activity (see Figure 3): 
- A level 1 of research and collection of information on the context and the studied situation. This level comprises control loops, which allow data validation.

- A level 2 of situation diagnosis, which corresponds to a loop of problem solving,

- Lastly, the level 3 of "action and decision-making", which leads to the proposal of countermeasures.

Various data perception stages lead to the second (diagnosis) phase. Finally a decision-making phase, with counter-measures to control situation, will be applied (action). These three levels are reinforced by control loops; for example, the information feedback of the operations theatre can trigger again the diagnosis and decisionmaking phases (see Figure 3). However, validation loops during information acquisition stage seem to be important outcomes: indeed these loops allow the individual or the group in the following stage of diagnosis. All information elements are checked near their source and it is only as from this moment that they are integrated in the diagnosis phase. These loops of validation are carried out by the reformulation of relevant information concerning the situation. These loops have several functions:

- $\quad$ To verify the validity of the information given by the source.

- To warm the team (other actors) of new information.

- To complete the information.

It is an informal mode of communication that has all its importance in team activity. It corresponds to a double task that makes it possible to adjust the common reference frame of the various actors.

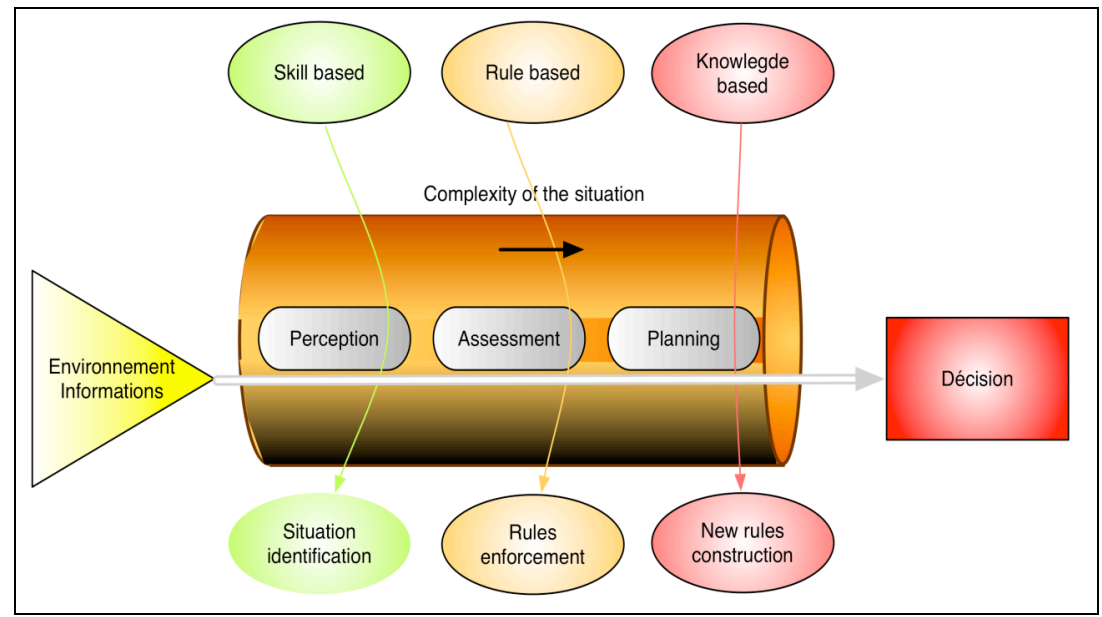

Figure 3. Proposition for an Alert Management Model

Moreover, according to the Rasmussen model (Rasmussen, 1994) and PRD model (Klein, 1993) (see Figure 3), in complex situations, the actions of perception, diagnosis and decision-making are based in majority on rules (write procedures) and knowledge (discussion between various experts). When experts are not able to identify the situation as a past similar one, they have to construct a new mode of response. For the more current situations, these stages are carried out quasi automatically (practices).

The phase of information acquisition is mainly based on individual modes (see Figure 1 and 4). The information acquisition phase is the one that employed individual mode. Each actor looks for cues in order to allow the team to understand the situation. This stage corresponds to "co-operation processes".

The situation assessment phases are mainly based on collaborative modes. This is a real collaboration. There is a dynamic allocation of functions between the different actors. They exchange their information elements in order to construct the common frame of reference (Hoc and Carlier, 2002).

The decision-making phase is codified but it concern collaboration mode too. So, the actors can begin diagnosis together and make decisions too. These stages correspond to collaboration processes. The team seems to function according to the same stages as the individual: information collection and validation, situation diagnosis and decision-making.

Moreover, cycles occur at these different stages. This is not a linear course of actions. In fact, a cycle of decision comprises several individuals performed by acquisition information phases, then a collaborative situation assessment phase before the first decision-making. There are recurrent cycles and decisions along a course of 
action as we can see in the Figure 1. A first decision (after the first decision cycle) is made in order to control the consequences of situation and then other decisions (after other cycles) allow the actors to adapt more precisely the countermeasures to the situation.

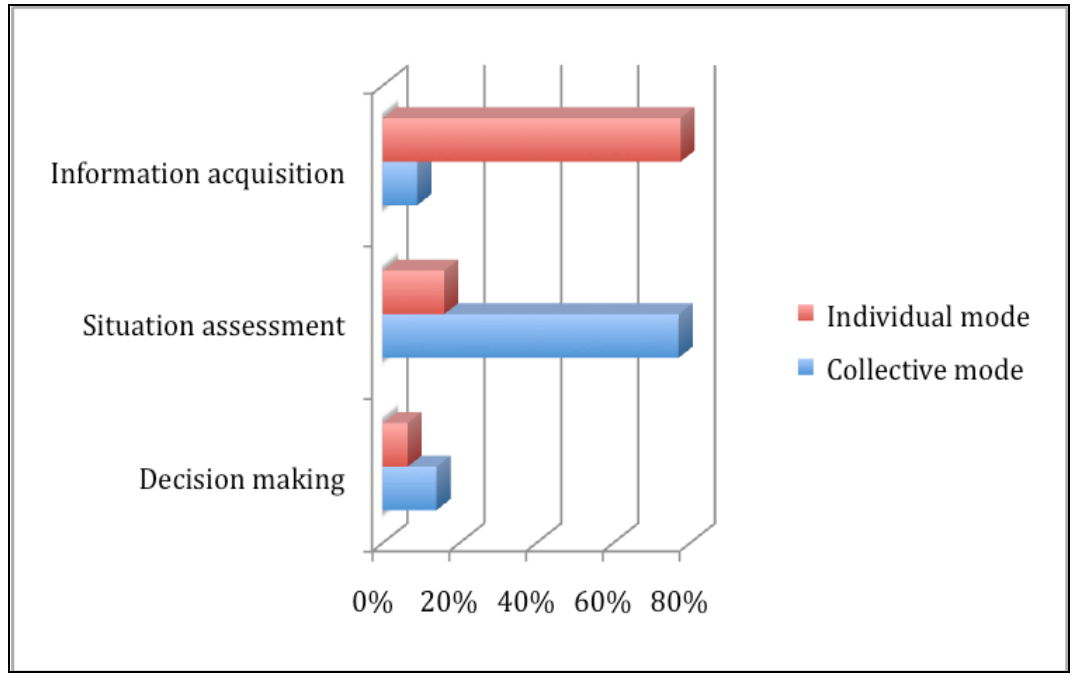

Figure 4. Effectives of the Individual and Collective Modes

\section{DISCUSSION AND CONCLUSION}

The majority of the events taken into account at the time of the exercise highlights collaborations during the situation assessment. These collaborations allow the various actors to create a common mental representation of the situation as this one evolves. They were present until the final process of decision-making. The obtained results have primary importance to prepare the following step: the analysis of an epidemiologic simulation of alarm in real dimension carried out in March 2008 in Djibouti.

In order to complete this work, it will be necessary to produce a model of alert management activity with regard to models of decision proposed by Rasmussen and Klein.

The idea defended in the $\mathrm{PhD}$ will consist applying this new model to an individual (operator alone) but also to a "Joint Cognitive System" (a group of operators and their systems).

In addition, these results made it possible to propose recommendations for the development and the efficiency of the future centre of epidemiologic expertise (CESIE).

Finally, we conclude that such complex situations are mainly managed in a real collaboration mode: there is a dynamic allocation of the functions between the actors of the team. They assess the situation and make decision together. The involved experts engaged in these situations and tasks, have to solicit other individuals and systems to obtain new information elements in order to solve the problem situation.

\section{ACKNOWLEDGMENTS}

The PhD work has been funded by DGA. We thank the team of the IMTSSA and the Chief consultant of Services J.P Boutin for their reception and their advices.

\section{REFERENCES}

Benchekroun, T.H., \& Weill-Fassina, A. (Eds.). (2000). Le travail collectif. Persectives actuelles en ergonomie. Toulouse Octarès.

Bisseret, A., Sébillotte, S., Falzon, P. (1999). Techniques pratiques pour l'étude des activités expertes. Toulouse : Octarès.

Chaudet, H., Pellegrin, L., Meynard, J-B., Texier, G., Tournebize, O., Queyriaux, B., Boutin, JP (2006). Web Services Based Syndromic Surveillance for Early Warning within French Forces. Studies in Health Technologies and Informatics, 124, 666-671. [PMID: 17108592, PubMed: in process].

Chaudet, H. (2006). Extending the event calculus for tracking epidemic spread. Artif Intell Med, 38(2), 137-56.

Christofferson, K. \& Woods, D.D. (2002). How to make automated systems team players. In E. Salas (Ed.), Advances in human performane and cognitive engineering research (pp. 2-12). Stamford, CT: JAI Pres/Elsevier.

Cooke, N,-J. (2004). Measuring team knowledge. Ibid. 
De Terssac G. et Chabaud C. (1990), Référentiel opératif commun et fiabilité, In J. Leplat et G. De Terssac (Eds.), Les Facteurs humaines de la fiabilité dans les systèmes complexes (pp. 111-139). Toulouse, F: Octarès.

Endsley, M. (1995). Measurement of situation awareness in dynamic systems. Human Factors, 37, 65-84

Gangemi, A. \& als. (2002). Sweetening ontologies with DOLCE. In A. Gomez-Pérez \& V-R. Benjamins (Eds.). Knowlegde Engineering and Knowledge Management, 13th International Conférence on Ontologies and the Semantic Web, EKAW 02, Siguenza, Spain, (pp. 166-81), Springer-VERLAG Eds, Berlin.

Frederico, P., A. (1995). Expert and novice recognition of similar situations. Human factors, 37(1), 105-122.

Hoc, J.-M., \& Amalberti, R. (1994). Diagnostic et prise de décision dans les situations dynamiques, Psychologie Française, 39 (2), 177-192.

Hoc, J.M. (1996). Supervision et contrôle de processus. La cognition en situation dynamique. Grenoble : Presses Universitaires de Grenoble.

Hollnagel, E., Woods, D. (2005), Joint Cognitive System: Foundations of Cognitive Systems Engineering. CRC Press.

Hutchins, E., 1995, Cognition in the Wild (Cambridge, MA: MIT Press).

Karsenty, L. \& Pavard, B. (1997). Différents niveaux d'analyse du contexte dans l'étude ergonomique du travail collectif. Réseaux, 85, 73-99.

Klein, G.A., Orasanu, J., Calderwood, R. \& Zsambok, C.E. (Eds). (1993) Decision making in action: Models and methods, Norwood, NJ: Ablex Publisher.

Leplat, J. (1994). Collective activity in work : some lines of research. Le travail Humain, 57 (3), 209-226.

Maggi, B. (1996). La régulation d'un processus d'action de travail; In P. Cazamian, F. Hubault, \& M. Noulin (Eds.), Traité d'ergonomie (pp. 637-662). Toulouse: Octarès.

Minsky, M. (1975). A Framework for Representing Knowledge. In P. H. Winston (Ed.), The Psychology of Computer Vision. McGraw-Hill.

Orasanu, J., \& Connolly, T. (1993). The reinvention of decision-making. In G.A. Klein, J. Orasanu \& R. Caderood, \& C. Zsambok (Eds.), Decision making in action: Models and methods (pp. 3-20). Norwood, NJ: Alex.

Patel, V.L., \& Arocha, J.F. (2001). The nature of constraints on collaborative decision making in healf care setting. In E. Salas, \& G.A. Klein (Eds.), Linking expertise and naturalistic decision-making (pp. 383-431). Mahwah, NJ: LEA.

Pellegrin, L., Bonnardel, N., Antonini, F., Albanese, J., Martin, C., Chaudet, H. (2007). Event Oriented représentation for collaborative activities (EORCA). A method for describing medical activities in severalyinjured patient management. Method of information in medecine, 46, 506-15.

Rasmussen, J., Pejtersen, AM., \& Goodstein, LP. (1994). Cognitive system engineering. New York: Wiley.

Rognin, L., Salembier, P., Zouinar, M. (2000). Cooperation, reliability of socio-technical systems and allocation of function. J. Human-computer studies, 52, 357-379.

Salas, E. \& Hendricks, H. (Eds.). Handbook of human factors methods. CRC Press, Boca, Raton, USA.

Savoyant, A. \& Leplat, J. (1993). Statut et fonction des communications dans l'activité des équipes de travail. Psychologie Française, 28 (3), 247-253.

Wallenius, K. (2002). A generic model of management and command and control. In 7th International Command and Control Research and technology symposium, 16-20 September, 2002, Quebec City, Canada. 